\title{
Canadian Journal of Gastroenterology Awards presented at Canadian Digestive Diseases Week 2012
}

$\mathrm{T}$ he 2012 Canadian Journal of Gastroenterology Awards were announced by Ann LeBlanc, Vice-President of Pulsus Group, during the Hot Off The Press: Late-breaking Publications from the GI Journals session at the CDDW meeting held in Montreal, Quebec, February 24 to 27, 2012.

These awards honour the founding Editors-in-Chief of the Canadian Journal of Gastroenterology, and are presented each year to individuals or groups that have made a significant contribution to the fields of gastroenterology or hepatology, as demonstrated by the impact of original research published in the Journal and judged by the Editor-in-Chief and Associate Editors.
Dr ABR Thomson/Dr CN Williams Award - the 2012 winners are Sylvain Coderre (Calgary, Alberta), John Anderson (United Kingdom), Remy Rikers (The Netherlands), Paul Dunckley (Calgary), Karen Holbrook (United Kingdom) and Kevin McLaughlin (Calgary) for their article, 'Early use of magnetic endoscopic imaging by novice colonoscopists: Improved performance without increase in workload' (Can J Gastroenterol 2010;24[12]:727-732).

Award of Distinction - the 2012 winners are M Zhang, J Uhanova and G Minuk from Winnipeg, Manitoba, for their article 'Liver transplant outcomes in a Canadian First Nations population' (Can J Gastroenterol 2011;25[6]:307-310). 


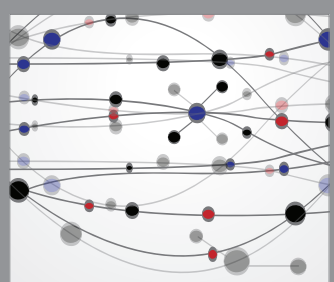

The Scientific World Journal
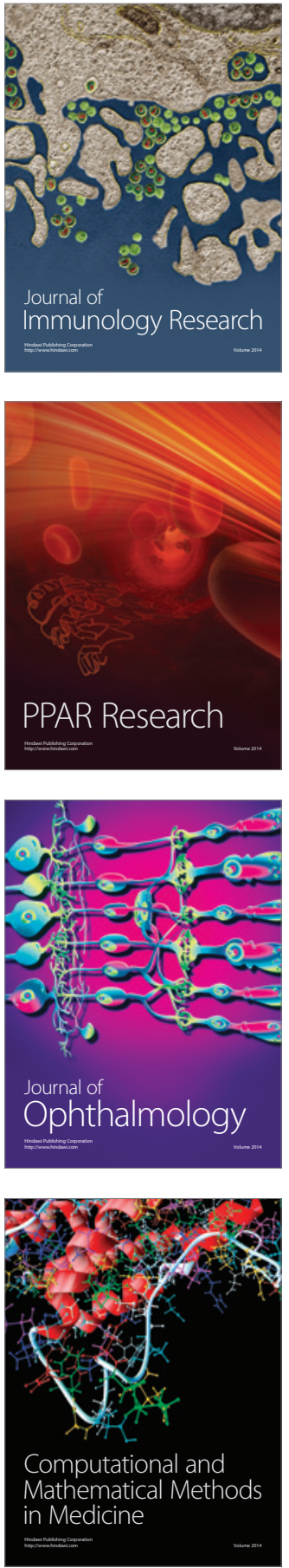

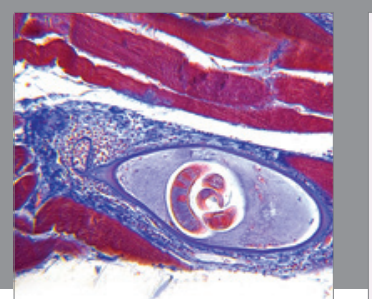

Gastroenterology Research and Practice

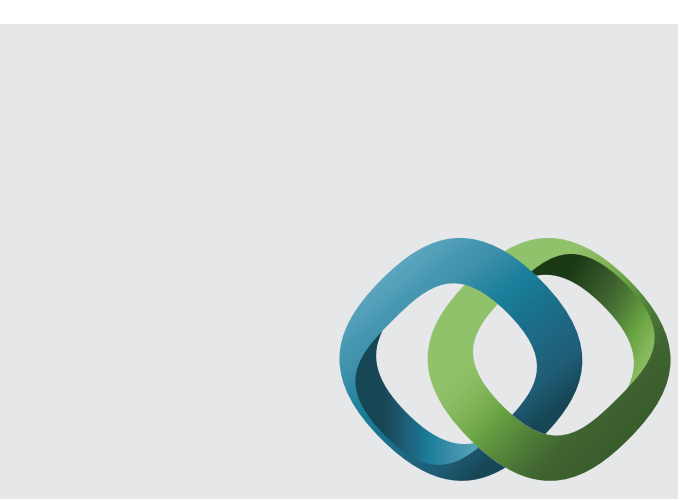

\section{Hindawi}

Submit your manuscripts at

http://www.hindawi.com
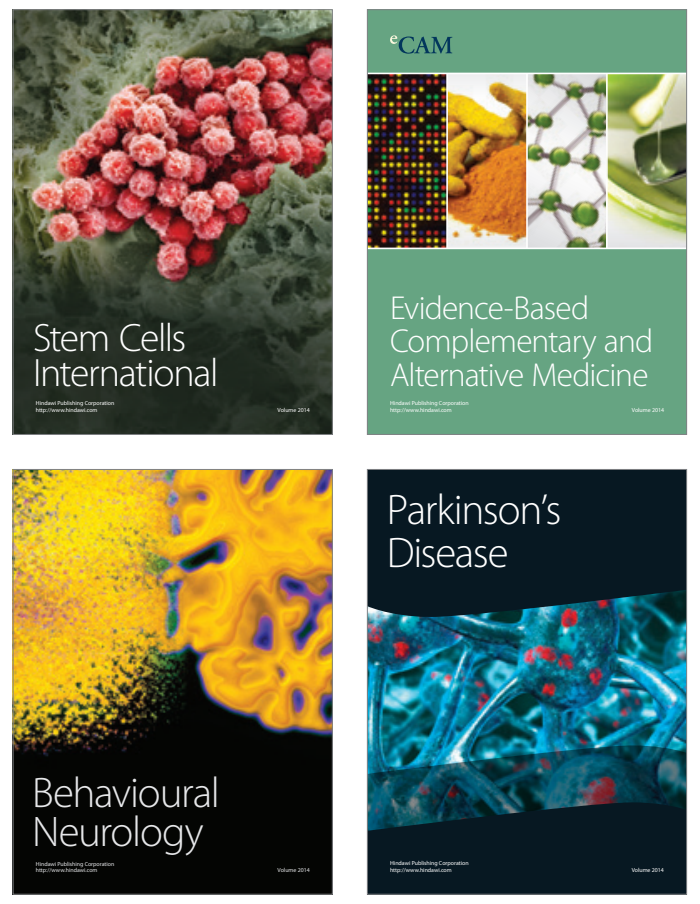
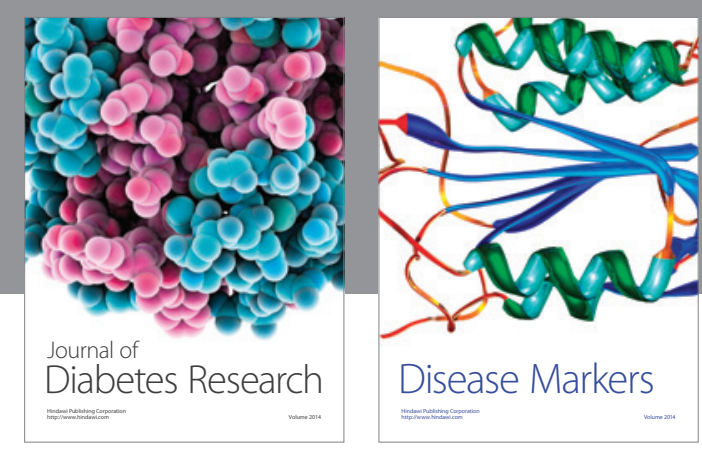

Disease Markers
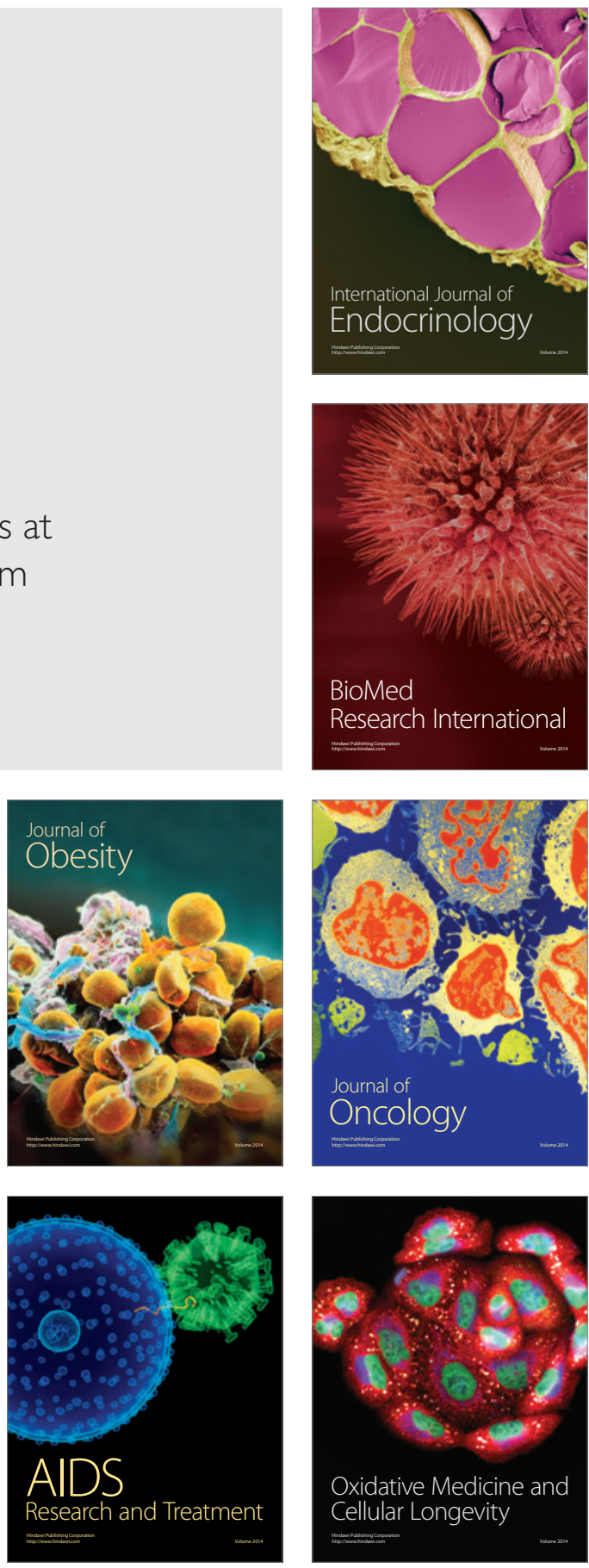